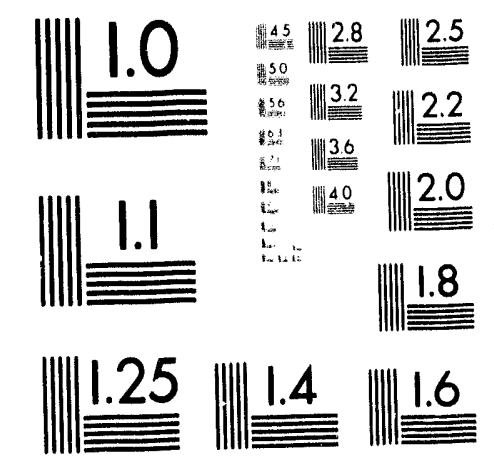



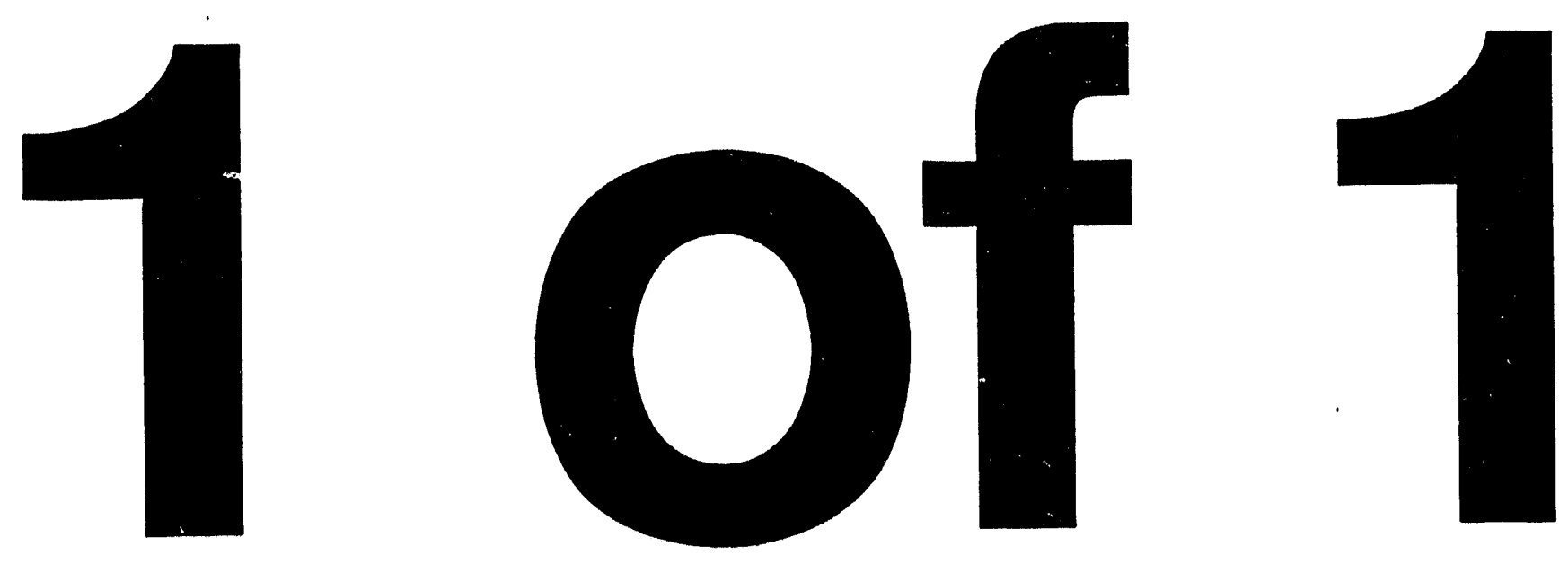

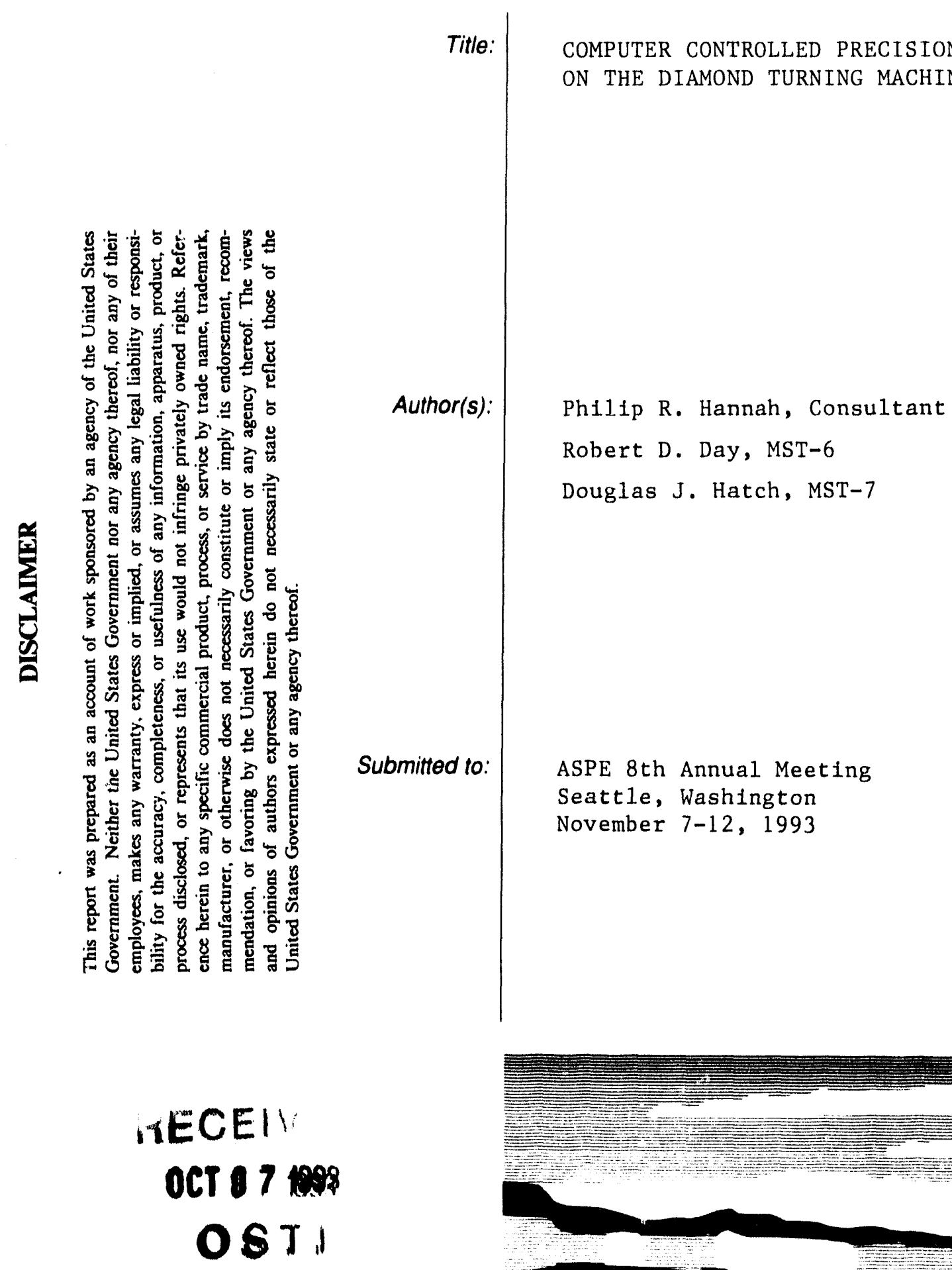

Submitted to:

ASPE 8th Annual Meeting

Seattle, Washington

November $7-12,1993$

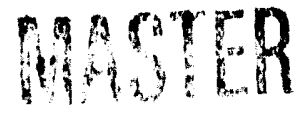

\section{Los Alamos}

NATIONAL LABORATORY

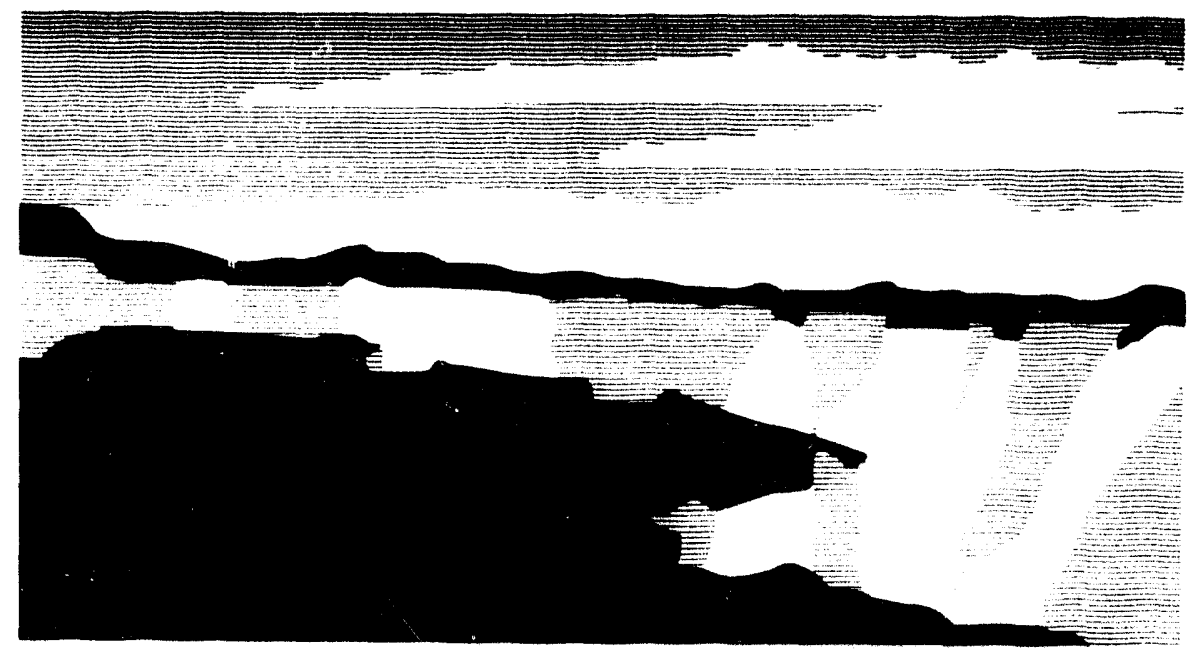

Los Alamos National Laboratory, an aftirmative action/equal opportunity emplóyer, is operated by the University of California tor the U.S. Department of Energy under contract W-7405-ENG-36. By acceptance of this article, the publisher recognizes that the U.S. Government retains a nonexclusive, royalty-free license to publish or reproduce the published form of this contribution, or to allow others to do so, for U.S. Government purposes. The Los Alamos National Laboratory requests that the publisher identily this article as work pertormed under the auspices of the U.S. Department of Energy. 


\title{
Computer Controlled Precision Optical Polishing on the Diamond Turning Machine
}

\author{
P. R. Hannah, R. D. Day, D. Hatch \\ Los Alamos National Laboratory \\ Los Alamos, NM 87545
}

\section{INTRODUCTION:}

This abstract reports the force and wear data required to predict the material removal, or wear, for the Numerical Controlled (N/C) polishing program. The program's aim is to provide the operator of a N/C diamond turning machine or N/C grinding machine with the wear characteristics necessary to achieve uniform material removal.

The first phase of the program looks at a rotating polishing wheel, moving from near the center to edge of a rotating glass disc (fig.1). Future phases will look at more complex shapes.

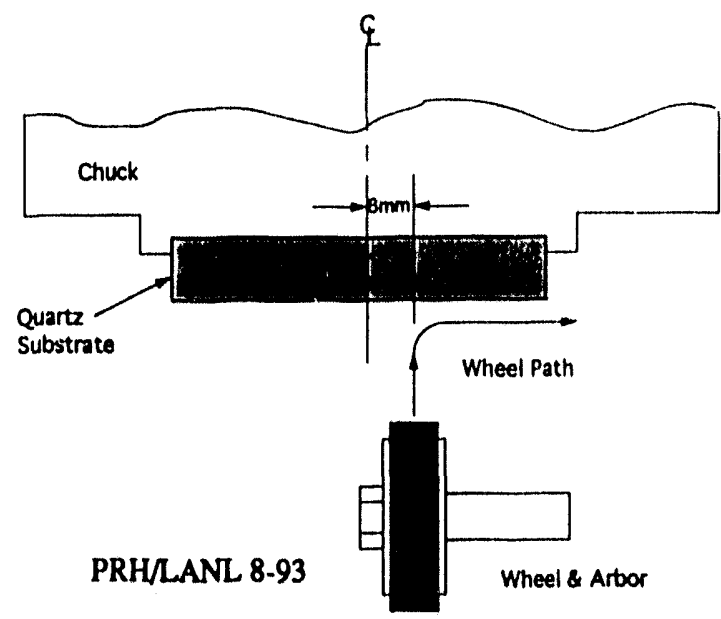

Figure 1 - Disc polishing detail

The amount of abrasive wear is proportional to the product of the pressure the polishing wheel exerts on the surface times the distance the surface travels relative to the polishing wheel [1]. This relationship expressed in equation form is known as Preston's equation:

$$
\Delta \mathrm{H}=(\mathrm{K})(\mathrm{P})(\Delta \mathrm{S})
$$

Where,

$$
\begin{aligned}
\Delta H & =\text { The amount of wear, } m \\
K & =\text { Inverse of specific energy required to remove material, } \mathrm{m}^{3} / \mathrm{J} \\
\mathrm{P} & =\text { The pressure exerted by the polishing wheel, } \mathrm{N} / \mathrm{m}^{3} \\
\Delta S & =\text { Distance the sample travels on the polishing wheel, } \mathrm{m}
\end{aligned}
$$

\section{DETERMINATION OF K PARAMETER FOR OUR PROCESS:}

In order to predict these wear characteristics, based simply on Preston's equation, the value of $K$ for our process must be known. So an experiment was performed to determine this value.

We used a polyurethane polishing wheel and a $75 \mathrm{~mm}$ diameter quartz substrate or disc. The wheel had a partial toric contour with a major radius of $200 \mathrm{~mm}$ and a minor radius of $18 \mathrm{~mm}$. 
The precision N/C diamond turning machine was a Moore M-18 AG, located at the Target Fabrication Facility, Los Alamos National Laboratory. The machine was equipped with an air bearing polishing head (fig.2) which was in turn mounted on a Kistler 3-axis force dynamometer (fig. 3). Force data from the dynamometer was amplified by a matching Kistler amplifier and then stored in a Nicolet storage oscilloscope. Figure 2 gives a detail of the polishing head/quartz substrate (75 mm dia.x $12.5 \mathrm{~mm}, \mathrm{~S} / \mathrm{N}$ 5) relationship, also shown is the position of the wheel plunges or polished zones on the substrate.

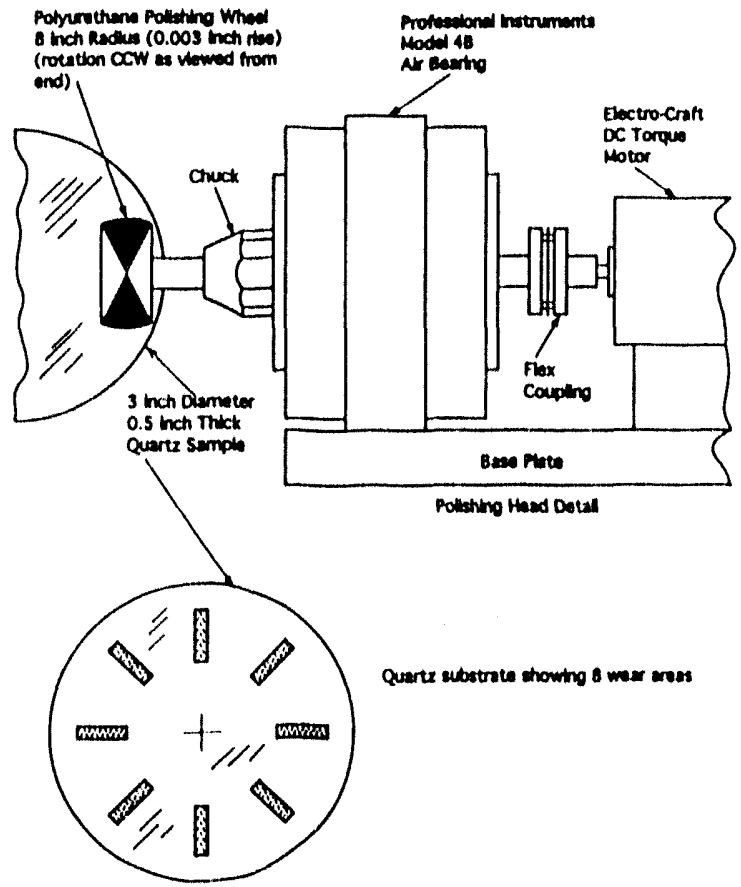

Figure 2 - Polishing head and wear test detail

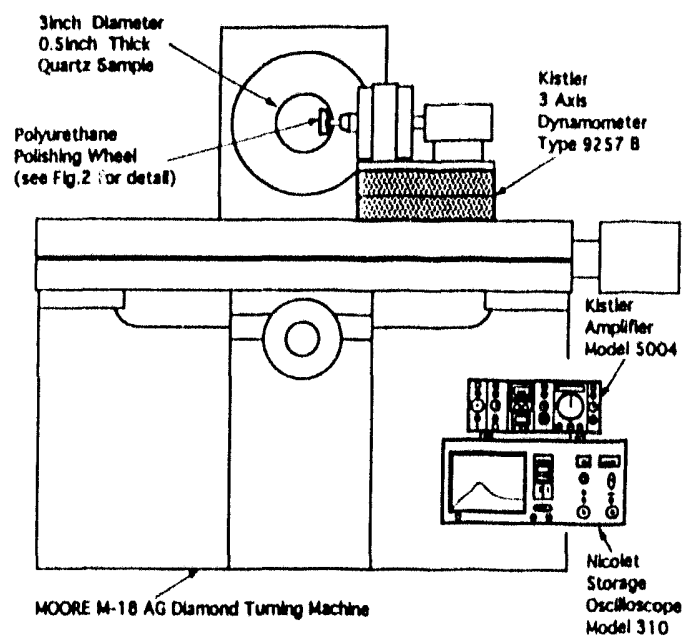

PRH/LANL 8.93

Figure 3 - Experimental Set-up

These polished zones were created by the polishing wheel rotating at $1000 \mathrm{rpm}$ being driven into the substrate to generate an average force which ranged from 1.2 to $6.7 \mathrm{~N}$. The polishing wheel was continuously saturated with a cerium oxide polishing compound (Rhodite 906). The dwell times varied from 25 to 55 seconds.

A series of 8 polished zones were made. These zones (fig.2) were then measured with a Zeiss light sectioning microscope. Depth and area data provided information that enabled the prediction of the wear characteristics for this particular system. A plot of depth vs. pressure $x$ distance is shown in figure 4. From equation 1 it can be seen that the slope of the line which bests fits the data in figure 4 is the value of $\mathrm{K}$ for our process. The equation shown inside the plot in is the equation this line. The value for $\mathrm{K}$ is $1 \times 10^{-12} \mathrm{~m}^{3} / \mathrm{J}$.

\section{PREDICTION OF SURFACE SHAPE BASED ON PRESTON'S EQUATION:}

To perform polishing on a DTM an assessment of how the polishing process will affect the surface shape must be determined. To better understand this effect a model of the polishing process for our configuration was performed based upon Preston's equation. The process modeled, was that of: a single polishing pass across the surface of a disc with the wheel starting near the center (fig.1), and moving up to the parts edge. 


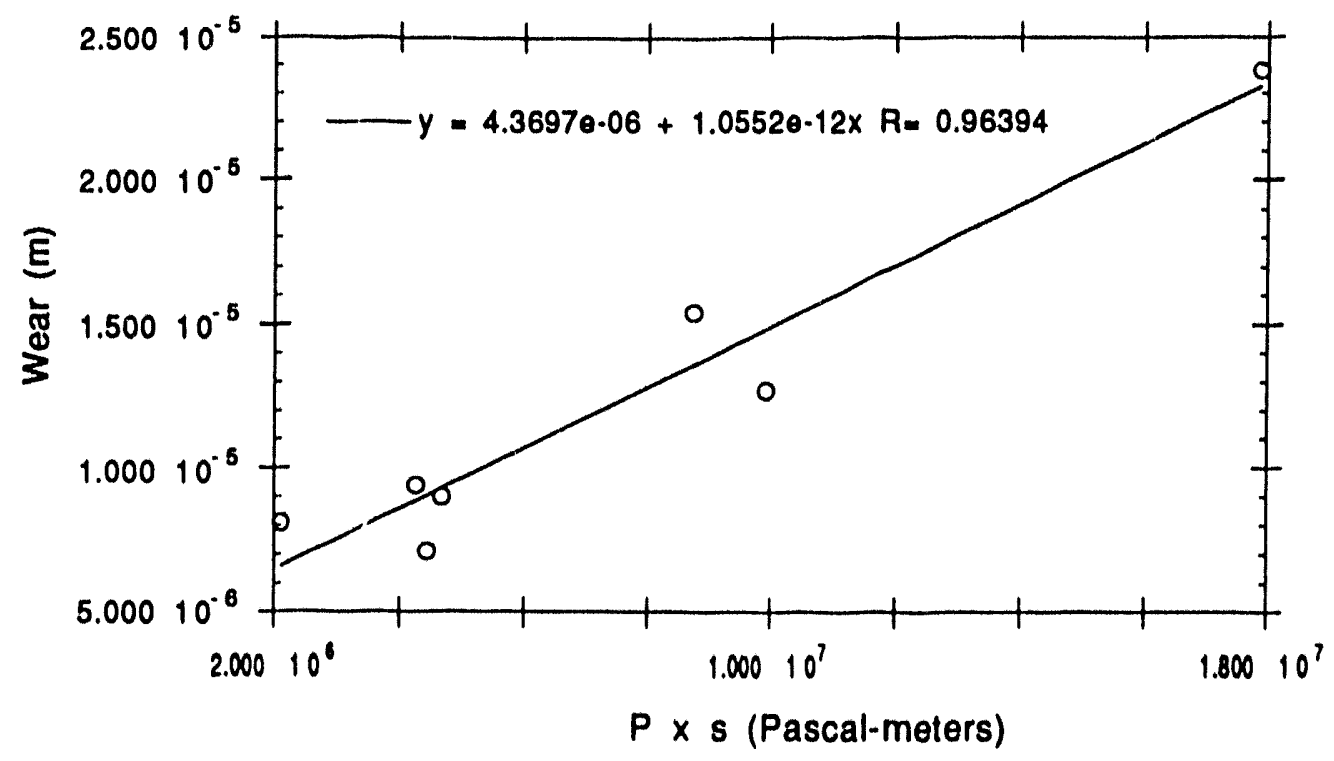

Figure 4 - Summary of wear data used to determine $\mathrm{K}$ for our process.

To aid in the modeling equation 1 must be rewritten in terms of velocity and time. The rate of wear is:

$$
\Delta \mathrm{H} / \Delta \mathrm{t}=(\mathrm{K})(\mathrm{P})(\Delta \mathrm{S} / \Delta \mathrm{t})
$$

or since $\Delta S / \Delta t=V$, equation (2) can be rewritten:

Where,

$$
\Delta H=(K)(P)(V) \Delta t
$$

$$
\begin{aligned}
& \mathrm{t}=\text { time, }, \\
& \mathrm{V}=\text { velocity }, \mathrm{m} / \mathrm{s}
\end{aligned}
$$

For our polishing configuration (see figure 1),

$$
\text { Where, }
$$

$r=$ radius on the part where the polishing is occurring, $m$

and

$$
\begin{aligned}
& \omega_{w p}=\text { angular velocity of the workpiece rad/s } \\
& R_{p w}=\text { radius of polishing wheel, } \mathrm{m} \\
& \omega_{\mathrm{pw}}=\text { angular velocity of the polishing wheel, } \mathrm{rad} / \mathrm{s}
\end{aligned}
$$

so

$$
\Delta t=\theta / \omega_{w p}
$$

$$
\Delta S=\left[(r)\left(\omega_{w p}\right)+\left(R_{p w}\right)\left(\omega_{p w}\right)\right]\left(\theta / \omega_{w p}\right)
$$

From figure 5 it is seen the approximation of $q=y / r$ may be made for small angles. (Even for angles as large as $30 \mathrm{deg}$ this approximation may be used for our analysis without much error.) 


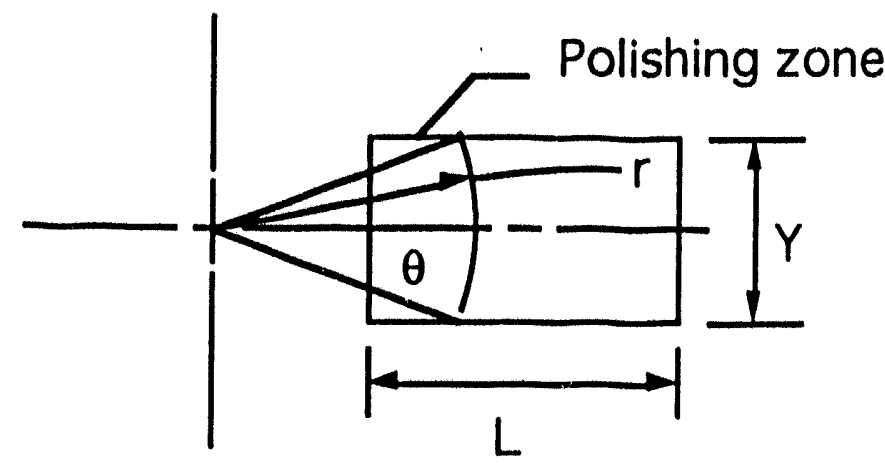

Figure 5 - Geometry of polishing zone

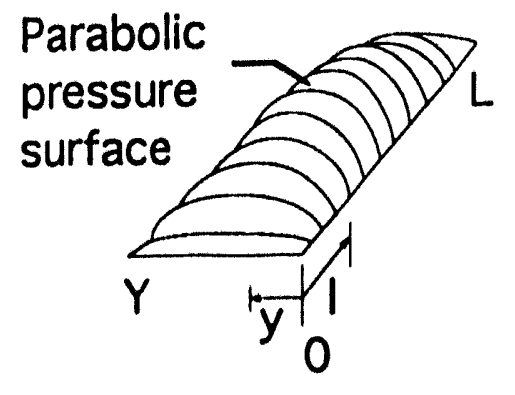

Figure 6 - Parabolic pressure profile

Substituting this relation into equation 6 and rearranging gives:

$$
\Delta S=(Y)\left[1+\left(R_{p w} / r\right)\left(\omega_{p w} / \omega_{w p}\right)\right]
$$

Now an expression for the pressure needs to be obtained. Measurements of the wear areas shown in figure 2 revealed that their 3-D profile looked much like the inverse of that shown in figure 6 . A curve fit to the data indicated that depth was a parabolic function in both the $y$ and $l$ directions. This implies that the pressure is a parabolic function in these directions also.

Since $P=0$ at $1=0$ and $L$, the expression for $P$ becomes:

$$
\begin{aligned}
P(1) & =(a)\left(l^{2}\right)-(a)(L)(l) \\
\text { where, } & \text { a coefficient determined from the measured force, } N / m^{4} \\
a & =a \text { con }
\end{aligned}
$$

Since all radii must pass through the entire polishing zone in the y-direction, an average value for the pressure may used for a given 1 -value. So the expression for $P(y)$ at a given $l$ is:

$$
P_{l}(y) \text { avg }=\int P_{1}(y) d y / \int d y
$$

For our situation of $P=0$ at $y=0$ and $Y$, and $P(Y / 2)=P \max =P(1)$, then:

$$
\mathrm{Pl}_{1}(\mathrm{y})_{\text {avg }}=(2 / 3) \mathrm{P}(\mathrm{l})
$$

Combining equations $1,7,8$, and 10 gives:

$$
\Delta \mathrm{H}=(\mathrm{K})(2 / 3)\left[(\mathrm{a})\left(\mathrm{l}^{2}\right)-(\mathrm{a})(\mathrm{L})(\mathrm{l})\right]\left[\left(1+\left(\mathrm{R}_{\mathrm{pw}} / \mathrm{r}\right)\left(\mathrm{w}_{\mathrm{pw}} / \mathrm{w}_{\mathrm{wp}}\right)\right](\mathrm{Y})\right.
$$

Equation 11, however, is the expression for only one pass through the polishing zone. The total wear is:

$$
H=\Sigma \Delta H=(N) \Delta H
$$

Where $\mathrm{N}$ is the number of passes a point on the workpiece makes through the polishing zone. The radial distance the polishing wheel will travel along the workpiece per revolution of the workpiece is:

$$
\Delta \mathrm{l}=\mathrm{f} / \mathrm{v}
$$


where,

$$
\begin{aligned}
& f=\text { the feedrate of the polishing wheel, } \mathrm{m} / \mathrm{s} \\
& \mathrm{V}=\text { the frequency of a point moving into the polishing zone, } \mathrm{Hz}
\end{aligned}
$$

Now

$$
N=1 / \Delta \mathrm{l}=\Sigma \Delta \mathrm{l} / \Delta \mathrm{l}=(\mathrm{V} / \mathrm{f}) \Sigma \Delta \mathrm{l}
$$

Combining equations 11,12 , and 13 gives:

$$
H(r)=(v / f)(K)(2 / 3)\left[\left(1+\left(R_{p w} / r\right)\left(w_{p w} / w_{w p}\right)\right](Y) \sum\left[(a)\left(1^{2}\right)-(a)(L)(l)\right] \Delta l\right.
$$

or as $\Delta \mathrm{l} \rightarrow 0$

$$
H(r)=(v / f)(K)(2 / 3)\left[\left(1+\left(R_{p w} / r\right)\left(w_{p w} / w_{w p}\right)\right](Y) \int\left[(a)\left(l^{2}\right)-(a)(L)(l)\right] d l\right.
$$

Equations 14 and 15 are the final ones used to describe our polishing process.

\section{EXPERIMENT TO TEST MODEL:}

The next test described here was designed to test the model of our process described above. Another $75 \mathrm{~mm}$ diameter disc of quartz (S/N 2) was placed on the diamond turning machine as before. Figure 7a shows a 3-D plot of the surface prior to polishing.

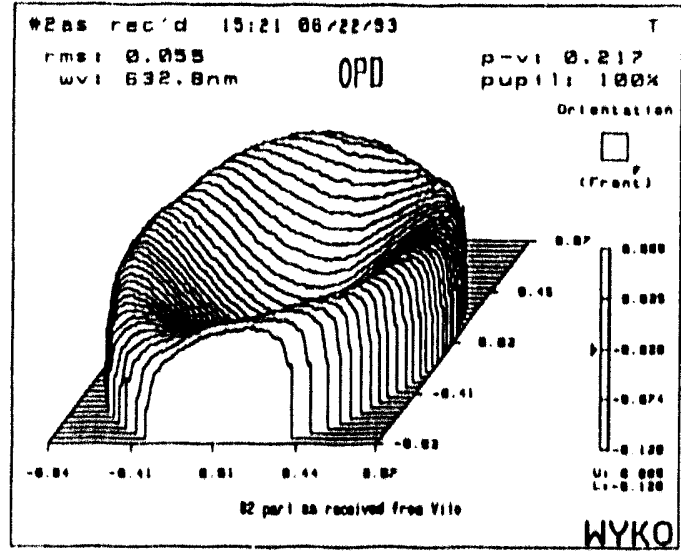

(a)

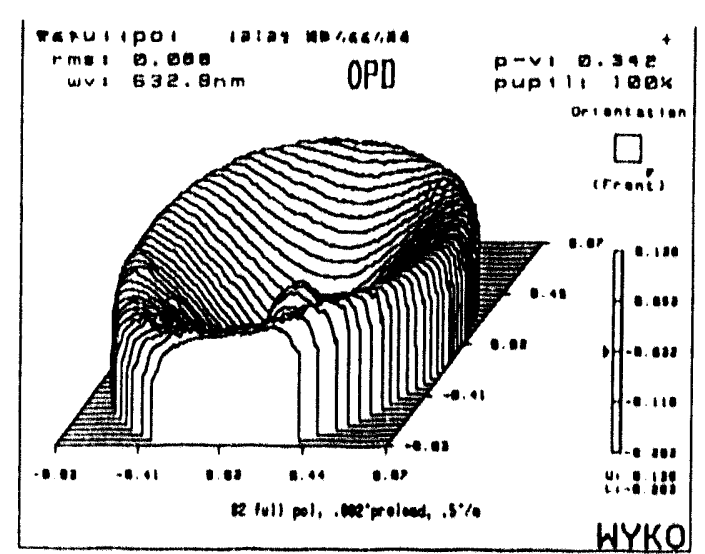

(b)

Figure 7 - Shape of disc \#2's shape: (a) before polishing, (b) after polishing.

For the test, the Quartz disc was rotated at $100 \mathrm{rpm}$. The polishing wheel was rotated at 1000 $\mathrm{rpm}$ with the same compound saturation rate as before, the average polishing force was measured to be $3.6 \mathrm{~N}$. The $X$-axis feed rate or wheel lateral movement was at $12.5 \mathrm{~mm}$ per min. A single pass was made with the wheel starting near the center (fig.4), and moving toward and past, the parts edge.

Upon completion of the test the part was evaluated. Figure $7 \mathrm{~b}$ is the after polishing 3-D and cross section plot. The reader should keep in mind that the overall peak to valley error in these before and after plots do not exceed 0.35 waves (@6328 )or $2.2 \mu$. Figure 9 shows the result of subtracting the before-polishing substrate surface from the after-polishing surface. 


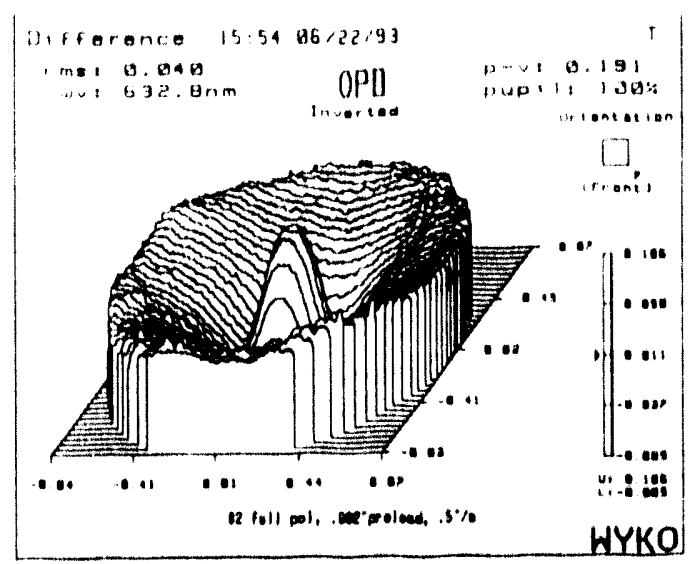

Figure 8 - Subtraction of disc \#2's shape before and after polishing

A computer program was written to calculate the shape based upon equation 14. For this program: $\mathrm{a}=-5.36 \times 10^{9} \mathrm{~N} / \mathrm{m}^{4}, \mathrm{Y}=3.5 \times 10^{-3} \mathrm{~m}, \mathrm{~L}=12 \times 10^{-3} \mathrm{~m}$. Figure 9 is a plot of the calculated and measured wear. The plot shows that the shape of workpiece after polishing can be predicted however the amount of material removal is not well predicted. This difference could be caused the way the value for $\mathrm{K}$ was measured, i.e. the workpiece was not turning when we made our plunges as shown in ligure 2 . Additional lests will be pertormed to resolve this discrepancy.

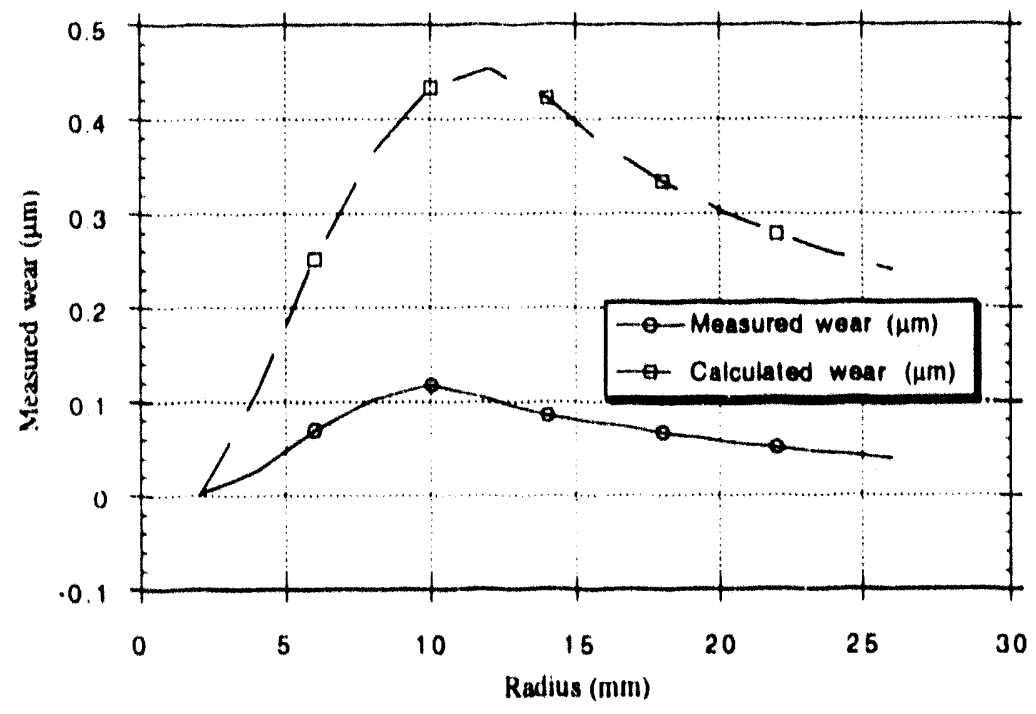

CONCLUSIONS:

Figure 9 - Comparison of calculated and measured wear

A model has been developed, using Preston's equation, to predict the shape of a workpiece after polishing on a N/C DTM. The model predicts the workpiece's general shape but does accurately predict the material removal. Additional work is needed to resolve this discrepancy.

\section{ACKNOWLEDGMENTS:}

The authors greatly appreciate the help of Dick Rhorer in setting up the Kistler Dynamometer. This work was performed under the auspices of the U.S. Department of Energy.

\section{REFERENCES:}

[1] N. J. Brown, Conventional Precision Optical Fabrication, Society for Photo-Optical Instrumentation Engineers Publication, p. 3 

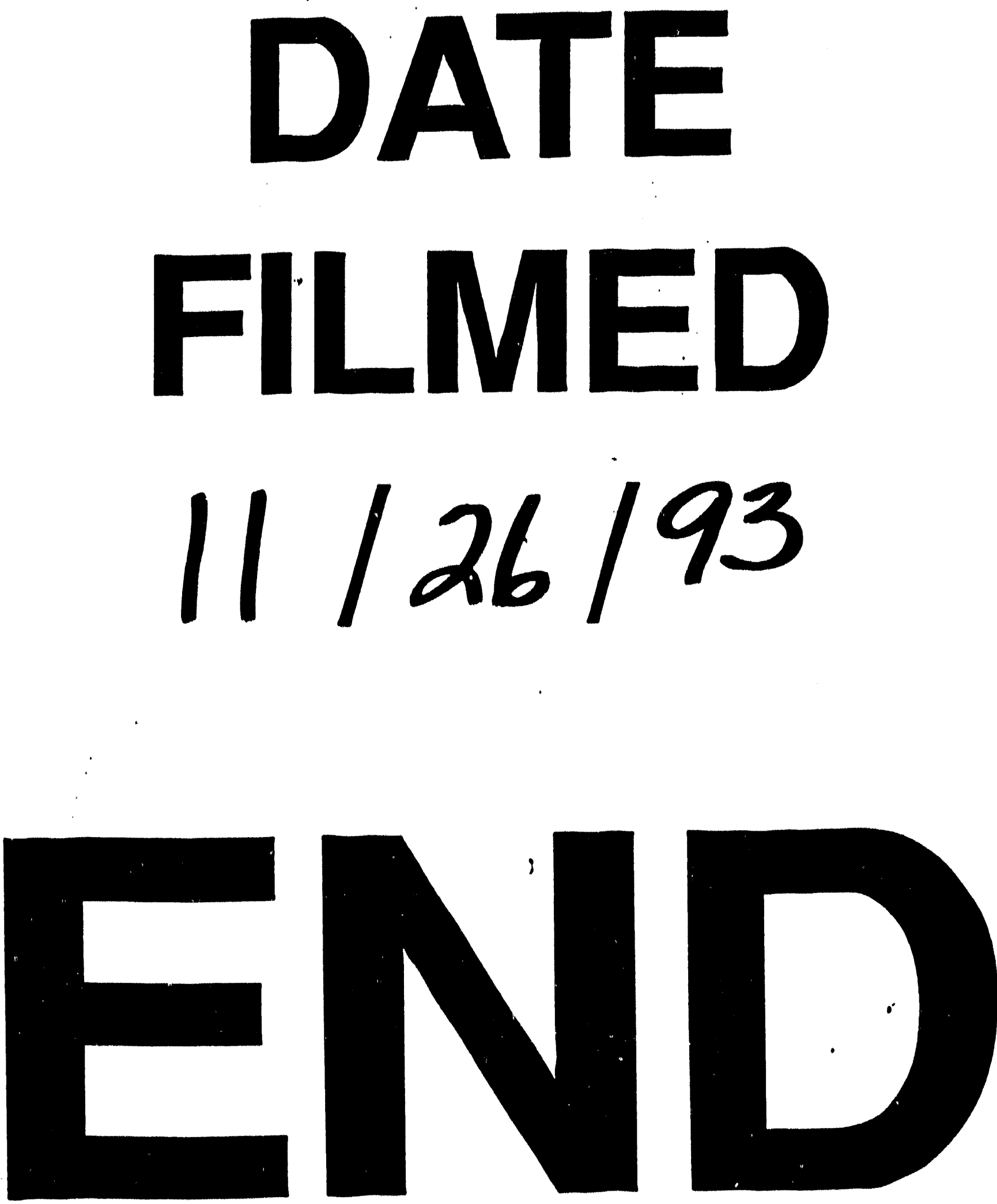


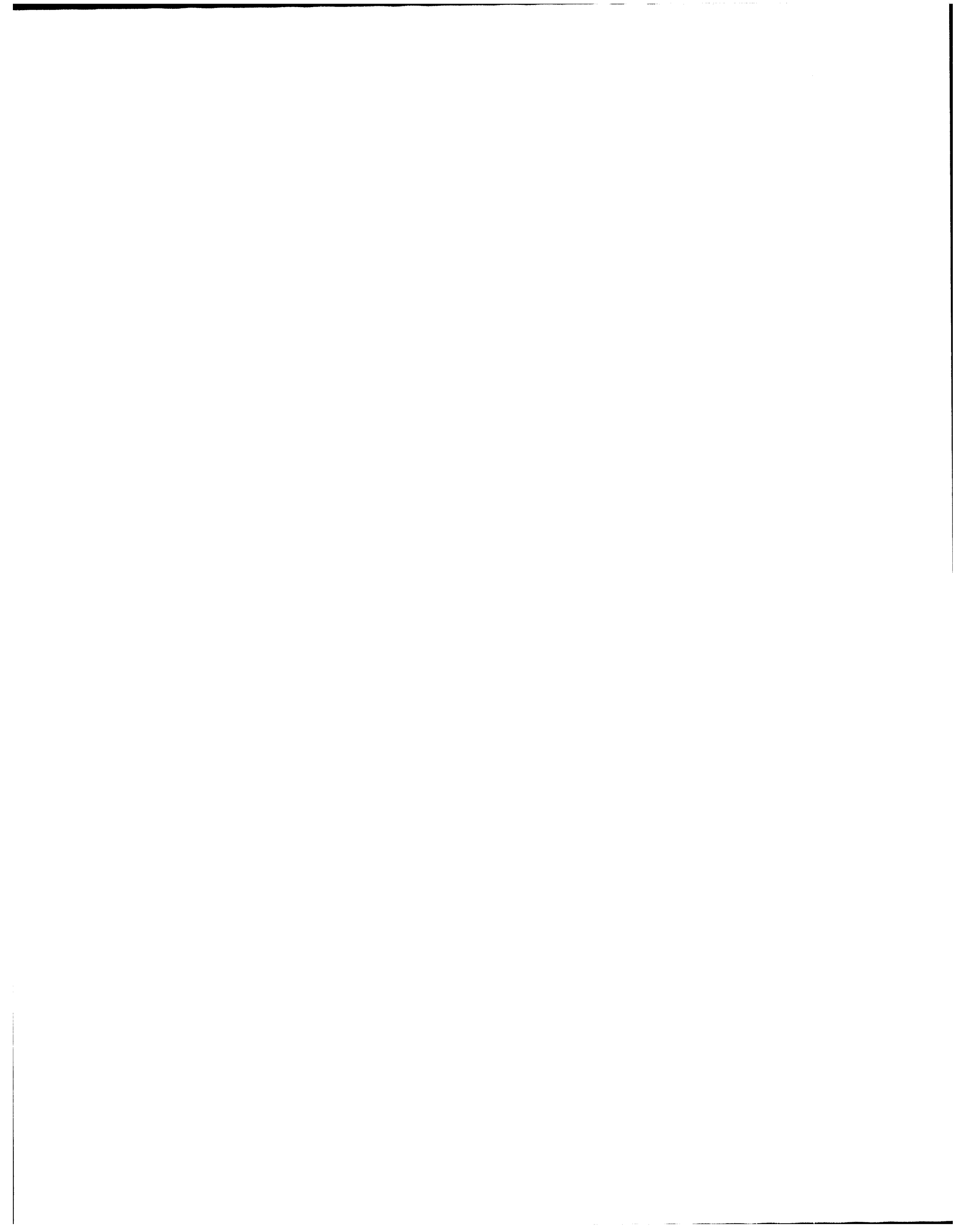

